\title{
International Graduate Students' Experiences of English as a Medium of Instruction (EMI) Courses in a Korean University
}

\author{
Yong-Jik Lee \\ Woosuk University, Wanju-Gun, South Korea \\ https://orcid.org/0000-0001-8783-2237 \\ Robert O. Davis \\ Hankuk University of Foreign Studies, Seoul, South Korea \\ https://orcid.org/0000-0002-6570-4477 \\ Yue Li \\ Woosuk University, Wanju-Gun, South Korea \\ https://orcid.org/0000-0002-6125-2709
}

\begin{abstract}
Owing to to the internalization of higher education, many universities in East Asia provide English as a medium of instruction (EMI) courses for international students. However, previous studies may not have strategically explored the perception of EMI courses for graduate programmes. Recognizing the gap in the literature, this study specifically focused on international graduate students' experiences of EMI courses in a Korean university. By implementing a mixed-method design, this study explored English language learnes' (ELLs) perceptions of EMI courses regarding i) ELLs' opinions on the effectiveness of EMI courses, ii) ELLs' attitudes towards EMI, and iii) their self-evaluation of English language ability. Data collection consisted of an end of the semester survey $(n=70)$ and focus group interviews $(n=9)$. The study results showed that i) ELLs showed positive attitudes towards EMI courses; ii) they perceived that the faculty's teaching methods are the core element to EMI course effectiveness; iii) their listening and reading skills were enhanced, and iv) ELLs with low English proficiency found EMI courses challenging to follow. Based on these results, several pedagogical implications are discussed regarding how to implement EMI courses effectively for diverse international students in ELT.
\end{abstract}

Keywords: EMI; International graduate students; English language learners (ELLs); English language teaching (ELT); Higher education 


\section{Introduction}

Owing to globalization, student populations at higher education institutions across the world are becoming more diverse (Galloway et al., 2020; Jon et al., 2014). To meet the learning needs of these diverse student populations, many universities in East Asia have adjusted course formats to include English as a medium of instruction (EMI) to accommodate international students (Hino, 2017). An EMI course is defined as the use of the English to teach academic subjects in countries where the first language of the majority of the population is not English (Dearden, 2014). Therefore, EMI bridges the needs of English language learners (ELLs) and the institutions where English is not the majority language (Dearden, 2014).

According to the Ministry of Education in Korea (2019), an increasing number of international students are studying in Korean universities. Overall, a total of 160,165 international students were registered in Korean higher education in 2019 before COVID-19. Among the diverse student population, a majority of international students are from China with 71,067 registered students. Graduate programmes at private universities in Korea have benefitted the most as international students study in Korea to obtain job promotions back home.

The literature on EMI courses in higher education has mostly focused on international students in undergraduate programmes (Kim et al., 2014); thus, it is not fully understood how international graduate students experience EMI courses in the East Asian context. Recognizing this gap in the literature, this study specifically focuses on international graduate students' experiences of EMI courses in a Korean university. By implementing the mixed method design, this study explored international graduate students' perceptions of EMI courses regarding i) students' opinions of the effectiveness of EMI courses, ii) students' attitudes towards EMI, and iii) their self-evaluation of English language ability.

\section{Literature Review}

\subsection{ELLs' Opinions on the Effectiveness of EMI Courses}

When considering the effectiveness of EMI courses, previous studies have reported that being a native or non-native English teacher is not a defining issue. Rather, recent studies showed that the effectiveness of EMI courses depends on the EMI faculty's linguistic competence, teaching methods, and intercultural competence (Inbar-Lourie \& Donitsa-Schmidt, 2020; Qiu \& Fang, 2019; Yuan et al., 2020). For example, Qiu and Fang (2019) explored ELLs' perceptions of two types of EMI instructors: i) native English-speaking instructors and ii) non-native English-speaking instructors. ELLs perceived that native English-speaking instructors employed interactive teaching methods with various activities and multimodality but did not recognize intercultural competence regarding ELLs. However, non-native English instructors showed higher intracultural competence, which indicated that they could communicate with ELLs about their learning difficulties more effectively. This study concluded that ELLs showed a preference for interactive and efficient EMI classrooms in which EMI instructors demonstrated intercultural and linguistic competence so that ELLs could solve learning problems and overcome linguistic barriers. 
In another study, Inbar-Lourie and Donitsa-Schmidt (2020) concluded that question of the preferred EMI lecturer could not be completely answered by the dichotomy of native and non-native English teachers. Instead, the authors argued that "desired EMI lecturers should be highly proficient in English, subject matter experts, able to simulate an international learning experience, display effective teaching pedagogies in both content and second language, and be familiar with the students' local language and culture" (pp. 301-302). This finding indicated that the EMI faculty's linguistic competency, teaching methods, and intercultural experiences are the core elements of the effectiveness of EMI courses (Inbar-Lourie \& Donitsa-Schmidt, 2020; Qiu \& Fang, 2019; Yuan et al., 2020).

\subsection{ELLs' Attitudes towards EMI Courses}

Students' course attitudes primarily focus on the course content, design, and administration (Hengsadeekul et al., 2014). If students favour the learning task through a positive outcome from the course, their attitudes towards the course could be enhanced (He \& Chiang, 2016). This implies that if ELLs develop a positive attitude toward EMI courses, their experience can be related to positive content and language development (He \& Chiang, 2016).

Several studies have documented how EMI can impact ELLs' course attitudes and satisfaction (Jensen \& Thøgersen, 2011; Muthanna \& Miao, 2015; Reilly, 2019; Yeh, 2014). For instance, Muthanna and Miao (2015) found that ELLs showed positive attitudes towards the EMI courses. Specifically, ELLs suggested that EMI courses helped foster a global friendship, obtain global leadership, and learn about famous international scholars. Reilly (2019) also reported a similar finding with ELLs. The author found that EMI courses were perceived positively and to be suitable for ELLs. ELLs perceived English skills as a valuable resource; thus, ELLs showed positive attitudes towards the multilingual language policy. Likewise, Yeh's (2014) study revealed that ELLs reported positive attitudes towards EMI courses. The results suggested that ELLs agreed with the benefits of EMI courses, such as enhancing English ability and future academic studies. Previous studies have shown that ELLs can have positive attitudes towards EMI courses due to potential future benefits, including their future job purposes, academic achievement, and becoming multilingual (Jensen \& Thøgersen, 2011; Muthanna \& Miao, 2015; Reilly, 2019; Yeh, 2014).

\subsection{EMI on ELLs' English Language Ability}

Previous studies have assessed the relationship between EMI and ELLs' language development (Belhiah \& Elhami, 2015; Coşgun \& Hasırc1, 2017). For instance, Coşgun and Hasırc1 (2017) investigated ELLs' perceptions of the EMI courses in relation to ELLs' English proficiency. Study results showed that EMI courses significantly improved students' reading, listening, and overall English proficiency. However, previous studies have also reported that EMI courses may not positively impact ELLs' language development. For example, Belhiah and Elhami (2015) concluded that ELLs struggled to learn the subject matter owing to their low level of proficiency in English. This study suggested that EMI programmes should consider a bilingual curriculum to enhance low proficiency ELLs' linguistic and biliteracy skills. Previous studies have summarized the impact of EMI on ELLs' English language ability. Some studies have reported 
positive impacts of EMI on ELLs' proficiency; however, other studies showed that if ELLs have low levels of English proficiency, the EMI courses may not positively influence their English language development (Belhiah \& Elhami, 2015; Coşgun \& Hasirc1, 2017).

By implementing the mixed-method design, this study explored international graduate students' perceptions of EMI courses regarding i) ELLs' opinions of the effectiveness of EMI courses, ii) ELLs' attitudes towards EMI, and iii) their selfevaluation of English language ability.

Q1: What are international students' opinions towards EMI courses after the semester?

Q2: What are international students' attitudes towards EMI courses after the semester?

Q3: How do international students evaluate their English language ability after taking EMI courses?

\section{Research Methodology}

\subsection{Research Context and Study Participants}

This study was conducted at a local private university in South Korea. The university has several graduate programmes that consist of international graduate students from China. This study focused on the general education department and culture and media department in the university because these two departments have the most graduate students. Three faculty members in two departments volunteered to participate in the EMI courses because they were quite confident in delivering EMI lectures. Three professors had had previous study abroad experience in the US for their doctoral degrees.

International graduate students' ages ranged from 25 to 47 , and consisted of firstyear master's students to third-year Ph.D. students. Out of 70 participants, three students had had previous study abroad experience in the UK or Russia before coming to Korea for graduate programmes. The purpose of studying abroad for Chinese graduate students is to promote their future job status. For instance, before coming to Korea, most Chinese PhD students were school staff, administrators, or part-time lecturers in their universities. After earning graduate degrees, these students could be promoted to tenure-track positions as full-time faculty in Chinese higher education.

\subsection{Research Instruments and Data Analysis}

An online survey was developed based upon previous studies exploring ELLs' attitudes, satisfaction, language ability, and the effectiveness of EMI courses (Byun et al., 2011; Hwang \& Ahn, 2011). Extracting relevant items from the existing literature (Byun et al., 2011; Hwang \& Ahn, 2011), the research team modified survey questions to fit into the current research. A total of 20 survey items were finalized. Specifically, the survey items consisted of i) students' personal and background information, ii) students' opinions of the effectiveness of EMI courses, iii) students' attitudes towards EMI courses, and iv) students' selfevaluation of their English language ability. 
This study implemented a mixed-methods research design. Data collection consisted of post-survey and post-interview in the 2021 spring semester. Before participating in the post-survey, informed consent forms for study participants were provided from the first author's university. The post-survey was conducted in the third week of June, and post-interviews followed. Eighty graduate students registered for EMI courses, and 70 completed the survey. Among them, nine study participants volunteered to participate in focus group interviews. Interviews were conducted with three participants as one group. For the purpose of quantitative data analysis, SPSS 26 was used to carry out descriptive statistics.

In relation to qualitative data collection and analysis, a graduate assistant in the education department conducted 40-50 minutes of focus-group interviews with nine volunteer participants who had completed their EMI surveys (See Appendix 1 for interview protocol). All interviews were conducted in Chinese and videorecorded through Zoom. Thematic analysis (Clarke \& Braun, 2014) was used to analyze the interview data. First, video recordings for interviews were listened to, re-listened to for accurate transcription and saved to Google Drive. Second, the research team developed initial codes and sub-codes while working through the interview transcriptions. Third, the research team developed themes to identify significant patterns of meaning. Fourth, several themes, including similarities and differences among participants, were aggravated into small numbers and reduced to the most frequently referred to categories. Fifth, the research team defined and renamed themes for abstraction and data reduction. In the last step, the interview data analysis was compared and contrasted to quantitative data analysis to create a final report. Table 1 shows a description of the interview participants.

Table 1: Interview participants

\begin{tabular}{|c|c|c|c|c|}
\hline $\begin{array}{c}\text { Interview } \\
\text { Participants }\end{array}$ & Gender/Age & $\begin{array}{c}\text { Year of the } \\
\text { Graduate } \\
\text { Program }\end{array}$ & $\begin{array}{c}\text { Previous EMI } \\
\text { Experience }\end{array}$ & $\begin{array}{c}\text { Previous Study } \\
\text { Abroad } \\
\text { Experience }\end{array}$ \\
\hline ELL1 & Female & First year & $\mathrm{X}$ & $\mathrm{X}$ \\
\hline ELL2 & Female & First year & $\mathrm{X}$ & $\mathrm{X}$ \\
\hline ELL3 & Female & First year & 0 & 0 \\
\hline ELL4 & Female & First year & 0 & 0 \\
\hline ELL5 & Female & First year & $\mathrm{X}$ & $\mathrm{X}$ \\
\hline ELL6 & Female & Second year & $\mathrm{X}$ & $\mathrm{X}$ \\
\hline ELL7 & Female & Second year & $\mathrm{X}$ & $\mathrm{X}$ \\
\hline ELL8 & Male & Second year & 0 & $\mathrm{X}$ \\
\hline ELL9 & Male & Second year & 0 & 0 \\
\hline
\end{tabular}

\section{Survey Results}

The post-test design evaluated international student's perceptions of EMI courses at a Korean university. The quantitative data sought to explore their opinions, attitudes, and the effectiveness of studying in English. See Table 2 for complete descriptive statistics for all opinion, attitude, and effectiveness questions.

Q1: What are international graduate students' opinions towards EMI courses after the semester?

International students' opinions were overall positive about EMI courses. Students strongly believed that EMI courses were necessary to help them prepare 
for a globalized world $(4.311 \pm 0.900)$, and they were satisfied with the courses offered $(4.067 \pm 0.837)$. Student opinions were positive regarding the idea that EMI courses could improve their English ability (4.022 \pm 1.118$)$; however, the standard deviation suggests that some students were somewhat negative regarding this question. International graduate students were satisfied with the EMI courses offered (3.956 \pm 0.903). However, students had the lowest opinion regarding needing to have mandatory EMI credits in their department courses (3.711 \pm 1.236).

Q2: What are international graduate students' attitudes towards EMI courses after the semester?

International graduate students' attitudes toward EMI courses were somewhat positive overall. Students were the most positive regarding their desire to improve their English through EMI courses (4.22 \pm 0.850$)$; However other aspects of attitude were lower. Their attitude toward becoming more familiar with the English language and culture (3.911 \pm 0.925$)$, willingness to spend extra time studying (3.844 \pm 1.186$)$, and attitude toward taking more EMI courses in the future $(3.800 \pm 1.100)$ were somewhat positive. The lowest ranking attitude was the burden they felt while taking EMI courses $(2.978 \pm 1.196)$, which was somewhat negative.

Q3: How do international students evaluate their English language ability after taking EMI courses?

The effectiveness of EMI classes ranged from positive to somewhat positive. International graduate students felt EMI courses helped them understand global education more than courses delivered only in Korean (4.178 \pm 0.936$)$, and EMI helped them better prepare for their future careers (4.022 \pm 0.988$)$. Other questions regarding the effectiveness of EMI courses, such as English ability being reduced, EMI courses being better than KMI courses for a future career, EMI improving learning motivation, and EMI courses improving the four skills, ranged from 3.778 \pm 1.106 to $3.689 \pm 1.104$.

Table 2: Descriptive statistics for EMI opinion, attitude, and effectiveness

\begin{tabular}{|l|l|l|}
\hline Question & M & (SD) \\
\hline Opinion & & \\
\hline $\begin{array}{l}\text { 1. I think that taking EMI courses is a necessary step for me to be } \\
\text { prepared for globalization and the internalization world. }\end{array}$ & 4.311 & $(0.900)$ \\
\hline $\begin{array}{l}\text { 2. Overall, I am quite satisfied with the quality of EMI courses that } \\
\text { are offered now. }\end{array}$ & 4.067 & $(0.837)$ \\
\hline $\begin{array}{l}\text { 3. I am quite satisfied with the diverse EMI courses that are offered } \\
\text { in my department. }\end{array}$ & 3.956 & $(0.903)$ \\
\hline $\begin{array}{l}\text { 4. I think that it is necessary to take certain EMI credits as mandatory } \\
\text { in my education department. }\end{array}$ & 3.711 & $(1.236)$ \\
\hline $\begin{array}{l}\text { 5. I think that opening/offering EMI courses in my department will } \\
\text { help me improve my English ability. }\end{array}$ & 4.022 & $(1.118)$ \\
\hline Attitude & & \\
\hline 1. I feel quite burdened when taking EMI courses. (R)* & 2.978 & $(1.196)$ \\
\hline $\begin{array}{l}\text { 2. I want to be more familiar with the English language and culture } \\
\text { through EMI courses. }\end{array}$ & 3.911 & $(0.925)$ \\
\hline
\end{tabular}




\begin{tabular}{|l|l|l|}
\hline 3. I want to improve my English ability through EMI courses. & 4.22 & $(0.850)$ \\
\hline 4. I am more willing to take EMI courses in the future. & 3.800 & $(1.100)$ \\
\hline $\begin{array}{l}\text { 5. I usually take more time studying materials in EMI courses as } \\
\text { opposed to KMI courses (KMI - Korean as a medium of instruction). }\end{array}$ & 3.844 & $(1.186)$ \\
\hline Effectiveness & & \\
\hline $\begin{array}{l}\text { 1. If I take EMI courses, my concerns about my English ability can be } \\
\text { reduced. }\end{array}$ & 3.711 & $(1.160)$ \\
\hline $\begin{array}{l}\text { 2. EMI courses can help me better understand the global educational } \\
\text { system, such as those of the US and Korea, as opposed to KMI } \\
\text { courses (KMI - Korean as a medium of instruction). }\end{array}$ & 4.178 & $(0.936)$ \\
\hline $\begin{array}{l}\text { 3. EMI courses will help me better prepare for my future career, such } \\
\text { as job purposes and pursuing further degrees. }\end{array}$ & 4.022 & $(0.988)$ \\
\hline $\begin{array}{l}\text { 4. EMI courses can help me improve my knowledge related to } \\
\text { education as a major as opposed to KMI courses. }\end{array}$ & 3.778 & $(1.106)$ \\
\hline $\begin{array}{l}\text { 5. EMI courses can help me improve my learning motivation and } \\
\text { interests regarding my major (education). }\end{array}$ & 3.778 & $(1.042)$ \\
\hline $\begin{array}{l}\text { 6. EMI courses can help me improve my English skills, such as } \\
\text { listening, speaking, reading, and writing. }\end{array}$ & 3.689 & $(1.104)$ \\
\hline
\end{tabular}

${ }^{*}(\mathrm{R})$ denotes reversed scored

\subsection{Findings from Interviews}

The interview analysis revealed international graduate students' perceptions in regard to i) attitudes towards EMI courses, ii) opinions of effective EMI courses, and iii) self-evaluation of English language ability.

First, in terms of students' attitudes towards EMI courses, they showed a strong willingness to attend more EMI courses in the following semesters because they were quite satisfied with the EMI content and lectures that the faculty provided. This finding indicated that students showed a positive attitude towards EMI courses. Here are some examples:

One EMI faculty constantly provided us with feedback on how to improve our English ability based on his own study abroad experience in the US. I want to take more EMI courses in the following semesters (Interview participant \#8).

Carefully listening to the professor's lecture every week was a constant input for improving my English listening skills (Interview participant \#9).

Some mentioned that if the courses were not in EMI format, they would probably not study English enthusiastically. They also remarked that EMI courses promoted their motivation to learn English because they will eventually become university professors in China. Thus, learning an academic language and having the ability to understand English articles is mandatory for them to pursue future academic careers. Here is one example:

My previous major was in Chinese literature, so when I was in a university, I had not taken any EMI courses. Since I am currently studying abroad in Korea, EMI courses were new to me and gave me a fresh eye on the importance of learning academic English for my future 
career. I do need to explore recent research trends in English articles for a better understanding of my field and discipline (Interview participant \#5).

Second, in terms of effective EMI courses, most of the interview participants responded that the quality and teaching methods of the EMI faculty are the core elements of effective EMI courses. For instance, they liked how the faculty delivered the course materials. Specifically, one EMI faculty implemented flipped learning (Sams \& Bergman, 2012) so that students were able to read English texts in advance. This flipped learning format provided ELLs with sufficient time and opportunities to explore English materials in advance.

Professors L sent us English materials through Wechat, and we can preview those before attending zoom synchronized class. During class, we discuss what we preview in the Zoom breakout sessions through discussions. This was a beneficial course structure because we needed some time to look up academic vocabulary from the textbook that we are not familiar with previously (Interview participant \#1).

Another example was that the EMI faculty used various YouTube resources related to content with English subtitles. Students liked supplementary videos because those resources helped ELLs understand the content much more effectively. Students thought that it was a good strategy to learn content in English subtitles. Here is one example.

I liked how professor K provided us with various YouTube videos with English subtitles. It actually helped me practice English listening skills while watching the video with texts (Interview participant \#2).

In relation to the effectiveness of EMI courses, ELLs emphasized that the quality of the EMI faculty was the core element. Thus, students discussed how the EMI faculty could be their role models for learning English with sufficient ability to deliver EMI courses. Here is one example:

I think that the EMI professors have high English proficiency with four language skills, so I do not have much difficulty understanding their English lectures. While taking EMI courses, I also believe that I can do EMI in my future teaching when I go back to China (Interview participant \#9).

Third, regarding EMI on ELLs' English language ability, most of them responded that EMI courses encouraged them to study English harder than before. When asked about which language skills that EMI courses assisted them to improve, most of them responded that their listening and reading skills were enhanced. Specifically, they explained that the EMI faculty's lecture was a great source of English input to improve their listening ability. Also, all reading resources were in English; thus, they believed that their academic vocabulary skills for reading could be improved. In addition, ELLs are required to write their master's theses and doctoral dissertations in English in graduate programmes in Korea. Thus, their English academic reading and writing skills should be enhanced. The interview analysis clearly showed that they were highly motivated and realized the importance of learning academic English during EMI courses. Here is one example. 
I will start writing my dissertation in the following semester. So these EMI courses helped me learn how to write academic English papers. The faculty lecture in terms of how to write an English paper as a non-native English speaker was really beneficial (Interview participant \#6).

EMI faculty utilized their own studying abroad experiences and strategically guided ELLs' academic language usage for effective studying abroad experiences. Students really appreciated the faculty's conscious efforts (Interview participant \#1).

However, during the interview, a fourth theme emerged in terms of difficulties and challenges that ELLs faced while taking EMI courses. When students have low levels of English ability, it was quite challenging for them to comprehend lectures in EMI courses fully. In this case, they preferred to have a translatorstudent who could help them when they have questions during the class.

One of the difficulties that I had was communicating with the professor directly. If I had a good English-speaking ability, I could ask more questions to the professor (Interview participant \# 7).

I preferred EMI courses where the translator-student attended. I saw a few students who felt frustrated when they could not fully comprehend the content. It was a challenging situation for those who have low English proficiency in EMI courses (Interview participant \# 8).

A few participants mentioned challenges and difficulties that they faced if their English proficiency was at beginner level and they had not taken EMI courses previously.

\section{Discussion}

This study focused on international graduate students' EMI course experiences at a Korean university. By implementing a mixed-method assessment, this study explored i) ELLs' attitudes towards EMI, ii) ELLs' opinions of the effectiveness of EMI courses, and iii) their self-evaluation of English language ability. The survey results showed that ELLs believed that EMI courses were necessary to prepare them for a globalized world $(4.311 \pm 0.900)$. This supports findings by Muthanna and Miao (2015) that students are keenly aware that English is the medium of communication for international communication. The conceptualization of how important English is as a global commodity could be viewed as a catalyst for higher self-evaluation of learning motivation $(3.778 \pm 1.042)$ and future career preparation $(4.022 \pm 0.988)$, as participants stated in their interviews. In terms of attitudes towards EMI courses, students were motivated to improve their English, and to spend extra time studying. However, the lowest ranking was observed with the burden students felt while taking EMI courses $(2.978 \pm 1.196)$. It is possible the burden referred to by students is related to the lower language capabilities of some students, since only three of the seventy students had studied abroad in the UK or Russia. This may support previous research by Cheng and Erben (2012) that indicated language anxiety might be a factor in EMI courses where language proficiency is at lower levels (Kim et al., 2014). 
Study findings from the interviews are aligned with previous studies that highlighted the importance of i) ELLs' attitudes towards EMI courses (Jensen \& Thøgersen, 2011; \& Miao, 2015; Reilly, 2019; Yeh, 2014), ii) ELLs' opinions of the effectiveness of EMI (Chu et al., 2018; Corrales et al., 2016; Fang \& Liu, 2020; Huang, 2015), iii) ELLs' self-evaluation of language ability (Belhiah \& Elhami, 2015; Coşgun \& Hasırc1, 2017), and iv) challenges that ELLs faced while taking EMI courses (Tsou \& Kao, 2017; Walkinshaw et al., 2017).

First, international graduate students showed positive attitudes towards EMI courses in terms of faculty lectures and the textbooks, and materials provided, including video resources with English subtitles. In addition, study participants showed a strong motivation to learn English through EMI courses for their future careers and were willing to take EMI courses in the following semester. Since most of the students are university lecturers in China wanting to promote their job status, they understood the importance of acquiring academic language skills. The interview analysis clearly showed that ELLs were highly motivated to improve their English ability through EMI courses.

Second, interview analysis revealed that the faculty's teaching methods and the quality of the EMI faculty are the core elements of the effectiveness of EMI courses. Specifically, ELLs liked the flipped learning course format because it allowed them to have sufficient time to cover the content while focusing on academic vocabulary. More importantly, since the EMI faculty had a studying-abroad experience in English-speaking countries, students liked the faculty's high levels of proficiency in convening the EMI courses. ELLs believe that the faculty is their role model so that they can also teach EMI in their future classrooms. When the EMI faculty explicitly focused on language skills when teaching the content, many ELLs appreciated the professors' conscious efforts.

Third, the interview analysis showed that ELLs' listening and reading skills were enhanced. After the EMI courses, self-evaluation indicated that EMI courses helped their development of listening and reading skills. They also responded that their English writing needed to be enhanced because they had to write their master's theses and PhD dissertations in English. Students said that EMI courses encouraged them to study English more diligently than before. Thus, the EMI course was a great motivator for ELLs to achieve academic English.

However, when ELLs have low levels of English proficiency in EMI courses, it was challenging for some students to follow lectures. Also, some reported they had never been exposed to EMI courses previously, so it was difficult for those students to understand EMI courses effectively. Thus, students recommend that one student be designated as a translator-student, so their comprehension could be enhanced by their having the ability to communicate with professors more effectively. This finding is aligned with previous studies that EMI courses can have limitations based on ELLs' language proficiency and specific higher education contexts (Tsou \& Kao, 2017; Walkinshaw et al., 2017). 


\section{Pedagogical Suggestions for Effective EMI Courses}

The first suggestion for effective EMI courses for a diverse student population is to consider the English proficiency of the ELLs before their participation in EMI classes. Findings from this study indicated that if ELLs possess high levels of English proficiency, they mentioned that EMI improved their English ability and helped them learn content. However, if their English ability is at lower levels, ELLs may experience language anxiety in EMI courses. Previous studies have reported critical evidence that EMI courses might have a different impact depending on ELLs' proficiency levels (Cheng \& Erben, 2012; He \& Chiang, 2016; Kim et al., 2014). Kim et al. (2014) found that ELLs did not feel EMI courses improved their English ability owing to their insufficient language proficiency. Therefore, the EMI faculty should critically examine the level of ELLs' proficiency before compiling the EMI courses.

The second suggestion is to incorporate ELLs' native language during EMI courses. The current study showed that ELLs preferred to have EMI courses when the faculty allowed code-switching between two languages with the help of a student translator. Several studies have reported that allowing the use of ELLs' native language can help them learn English and understand the content of EMI courses better (Kuteeva, 2020). Thus, it is recommended that the EMI curriculum for international students in higher education needs to advocate translingual practices that enable ELLs to learn content and language simultaneously. Many studies have found that translanguaging in EMI courses has a positive impact on ELLs' content and language learning and development (Kuteeva, 2020). Thus, when the EMI faculty allow ELLs to practise a translingual environment, ELLs' satisfaction with EMI courses can be much more positive as opposed to Englishonly instruction (Yuan et al., 2020).

The third suggestion is to provide intensive professional development for university faculty. The results from the current study proved that ELLs were willing to take more EMI courses when qualified faculty offered such courses. In addition, ELLs preferred to have faculty who had been exposed to cultural and linguistic diversity, such as previous teaching experience with international students or faculty who had study-abroad experience. Several studies reported that the preferred EMI lecturer is not necessarily a native English speaker (InbarLourie \& Donitsa-Schmidt, 2020; Qiu \& Fang, 2019). Instead, the desired EMI faculty should be subject matter experts, obtain effective teaching pedagogy in both content and language and be familiar with the ELLs' language and culture (Inbar-Lourie \& Donitsa-Schmidt, 2020; Qiu \& Fang, 2019).

Since many international students visit East Asian universities through studyabroad programmes, it is crucial for higher education to provide intensive professional development for EMI faculty. Also, the faculty should be equipped with the mindset of becoming a culturally and linguistically responsive teacher (Lucas et al., 2008; Martin \& Strom, 2016). When the faculty is able to conduct culturally and linguistically responsive teaching, ELLs' satisfaction towards EMI courses can be improved. Future studies need to investigate further the relationship in terms of how translingual practice can impact EMI courses because 
this research area will provide better insight into effective EMI implementation for diverse student populations (Hino, 2017).

\section{Limitations}

Although findings from this study contribute to the field of knowledge and practice related to EMI courses for international graduate students, there are limitations that should be addressed. First, participants from this study were international graduate students at one private university in South Korea. Since EMI courses vary from university to university around the world, findings related to EMI courses at the current university may differ from findings in other programmes. Larger scale studies with longitude research design could provide additional data and insights related to this field.

It should also be noted that the survey used for this study was modified by the researchers. It is possible that questions that were left out may have yielded additional findings and suggestions related to EMI courses for international graduate students. Also, it is noted that the results from this study were from ELLs' self-evaluation of their English ability. Future studies could investigate ELLs' actual English language proficiency through EMI courses by using official English level tests, such as TOEFL. Lastly, this research did not employ a pre-and post-survey. Future research should examine ELLs' opinions, attitudes, and selfevaluations before and after the course to gain a better understanding of how EMI courses impact international graduate students.

\section{Conflict of Interests}

On behalf of all authors, the corresponding author states that there is no conflict of interest.

\section{References}

Belhiah, H., \& Elhami, M. (2015). English as a medium of instruction in the Gulf: When students and teachers speak. Language Policy, 14(1), 3-23. https://doi.org/10.1007/s10993-014-9336-9

Byun, K., Chu, H., Kim, M., Park, I., Kim, S., \& Jung, J. (2011). English-medium teaching in Korean higher education: Policy debates and reality. Higher Education, 62, 431449. https://doi.org/10.1007/s10734-010-9397-4

Cheng, R., \& Erben, A. (2012). Language anxiety: Experiences of Chinese graduate students at U.S. higher institutions. Journal of Studies in International Education, 16, 477-497. https://doi.org/10.1177/1028315311421841

Chu, H. N. R., Lee, W. S., \& Brien, P. W. (2018). Student satisfaction in an undergraduate international business EMI program: A case in southern Taiwan. Journal of Studies in International Education, 22(3), 198-209. https://doi.org/10.1177/1028315317748525

Clarke, V., \& Braun, V. (2014). Thematic analysis. In T.Teo (Ed.) Encyclopedia of critical psychology (pp. 1947-1952). Springer.

Corrales, K. A., Rey, L. A. P., \& Escamilla, N. S. (2016). Is EMI enough? Perceptions from university professors and students. Latin American Journal of Content $\mathcal{E}$ Language Integrated Learning, 9(2). https://doi.org/10.5294/7094

Coşgun, G., \& Hasırcı, B. (2017). The impact of English medium instruction (EMI) on students' language abilities. International Journal of Curriculum and Instruction. 9(2), 11-20. http://ijci.wcci-international.org/index.php/IJCI/article/view/73 
Dearden, J. (2014). English as a medium of instruction - A growing global phenomenon. British Council.

Fang, F., \& Liu, Y. (2020). Using all English is not always meaningful: Stakeholders' perspectives on the use of and attitudes towards translanguaging at a Chinese university. Lingua, 247, 102959. https://doi.org/10.1016/j.lingua.2020.102959

Galloway, N., Numajiri, T., \& Rees, N. (2020). The 'internationalisation', or 'Englishisation', of higher education in East Asia. Higher Education, 80(3), 395-414. https://link.springer.com/content/pdf/10.1007/s10734-019-00486-1.pdf

Gregersen, T., \& Horwitz, E. K. (2002). Language learning and perfectionism: Anxious and non-anxious language learners' reactions to their own oral performance. The Modern Language Journal,86(4), 562-570. https://doi.org/10.1111/15404781.00161

Hengsadeekul, C., Koul, R., \& Kaewkuekool, S. (2014). Motivational orientation and preference for English-medium programs in Thailand. International Journal of Educational Research, 66, 35-44. https://www.sciencedirect.com/science/article/pii/S0883035514000214

He, J. J., \& Chiang, S. Y. (2016). Challenges to English-medium instruction (EMI) for international students in China: A learners' perspective: English-medium education aims to accommodate international students into Chinese universities, but how well is it working? English Today, 32(4), 63-67. https://doi.org/10.1017/S0266078416000390

Helm, F. (2020). EMI, internationalisation, and the digital. International Journal of Bilingual $\begin{array}{llll}\text { Education and 314-325. } & \end{array}$ https://doi.org/10.1080/13670050.2019.1643823

Hino, N. (2017). The significance of EMI for the learning of EIL in higher education: Four cases from Japan. In B. Fenton-Smith, P. Humphreys \& I. Walkinshaw (eds.), English Medium Instruction in Higher Education in Asia-Pacific (pp. 115-131). Springer. https:/ /link.springer.com/chapter/10.1007/978-3-319-51976-0_7

Hwang, J. B., \& Ahn, H. D. (2011). The effects of college-level English-mediated instruction on students' acquisition of content knowledge and English competence. Korean Journal of English Language and Linguistics, 11(1), 77-97. http://home.konkuk.ac.kr/ hdahn/pub/2011EngLecture.pdf

Huang, D. F. (2015). Exploring and assessing effectiveness of English medium instruction courses: The students' perspectives. Procedia-Social and Behavioral Sciences, 173, 7178. https://doi.org/10.1016/j.sbspro.2015.02.033

Inbar-Lourie, O., \& Donitsa-Schmidt, S. (2020). EMI lecturers in international universities: Is a native/non-native English-speaking background relevant? International Journal of Bilingual Education and Bilingualism, 23(3), 301-313. https:// doi.org/10.1080/13670050.2019.1652558

Jensen, C., \& Thøgersen, J. (2011). Danish university lecturers' attitudes towards English as the medium of instruction. Ibérica, Revista de la Asociación Europea de Lenguas para Fines Especificos, 22, 13-33. https://www.redalyc.org/pdf/2870/287023888002.pdf

Jon, J. E., Lee, J. J., \& Byun, K. (2014). The emergence of a regional hub: Comparing international student choices and experiences in South Korea. Higher Education, 67(5), 691-710. https://doi.org/10.1007/s10734-013-9674-0

Karakas, A. (2017). The forgotten voices in higher education: Students' satisfaction with English-medium instruction. The Journal of English as an International Language, 12(1), 1-14. https:// files.eric.ed.gov/fulltext/ED574759.pdf

Kim, J., Tatar, B., \& Choi, J. (2014). Emerging culture of English-medium instruction in Korea: Experiences of Korean and international students. Language and 
Intercultural Communication, 441-459. https:/ / doi.org/10.1080/14708477.2014.946038

Kuteeva, M. (2020). Revisiting the 'E'en EMI: students' perceptions of standard English, lingua franca and translingual practices. International Journal of Bilingual Education and Bilingualism, 23(3), 287-300. https:/ / doi.org/10.1080/13670050.2019.1637395

Lucas, T., Villegas, A. M., \& Freedson-Gonzalez, M. (2008). Linguistically responsive teacher education: Preparing classroom teachers to teach English language learners. Journal of Teacher Education, 59(4), 361-373. https://doi.org/10.1177/0022487108322110

Martin, A. D., \& Strom, K. J. (2016). Toward a linguistically responsive teacher identity: An empirical review of the literature. International Multilingual Research Journal, 10(4), 239-253. https:/ / doi.org/10.1080/19313152.2016.1189799

Ministry of Education in Korea (2019). The recent statistics of the number of international students in Korean higher education. http:/ / english.moe.go.kr/sub/info.do?m=020105\&s=english

Muthanna, A., \& Miao, P. (2015). Chinese students' attitudes towards the use of Englishmedium instruction into the curriculum courses: A case study of a national key university in Beijing. Journal of Education and Training Studies , 3(5), 59-69.

Qiu, X., \& Fang, C. (2019). Creating an effective English-medium instruction (EMI) classroom: Chinese undergraduate students' perceptions of native and non-native English-speaking content teachers and their experiences. International Journal of Bilingual Education and Bilingualism, 1-15. https://doi.org/10.1080/13670050.2019.1707769

Reilly, C. (2019). Attitudes towards English as a medium of instruction in Malawian universities. English Academy Review, 36(1), 32-45. https:// doi.org/10.1080/10131752.2019.1582150

Tsou, W., \& Kao, S. M. (2017). Overview of EMI development. In W.Tsou, \& S-M. Kao (Eds.), English as a medium of instruction in higher education (pp. 3-18). Springer. https:/ / link.springer.com/chapter/10.1007/978-981-10-4645-2_1

Walkinshaw, I., Fenton-Smith, B., \& Humphreys, P. (2017). EMI issues and challenges in Asia-Pacific higher education: An introduction. In English medium instruction in higher education in Asia-Pacific (pp. 1-18). Springer. https:/ / link.springer.com/chapter/10.1007/978-3-319-51976-0_1

Yeh, C. C. (2014). Taiwanese students' experiences and attitudes towards English-medium courses in tertiary education. RELC Journal, 45(3), 305-319. https://doi.org/10.1177/0033688214555358

Yuan, R., Chen, Y., \& Peng, J. (2020). Understanding university teachers' beliefs and practice in using English as a medium of instruction. Teaching in Higher Education, 25(1), 1-16. https://doi.org/10.1080/13562517.2020.1715936

\section{Appendix 1. Interview Protocol}

1. Why do you take EMI courses this semester?

2. What do you think about the quality of EMI courses offered this semester?

3. What do you think about the faculty's teaching methods of EMI courses offered this semester?

4. How do EMI courses influence your English ability?

5. How do EMI courses influence learning motivation and interests?

6. How do EMI courses influence your future job and career?

7. Are you willing to take more EMI courses in the future? 